\title{
Gonadal Steroids Exert Facilitating and "Buffering" Effects on Glucocorticoid-Mediated Transcriptional Regulation of Corticotropin-Releasing Hormone and Corticosteroid Receptor Genes in Rat Brain
}

\author{
Vladimir K. Patchev and Osborne F. X. Almeida \\ Department of Neuroendocrinology, Max Planck Institute of Psychiatry, Clinical Institute, 80804 Munich, Germany
}

Gonadal steroids profoundly influence several brain functions and are apparently responsible for gender-specific differences in the regulation of hypothalamic-pituitary-adrenal (HPA) secretions. In this study, we examined the so-called "activational" effects of gonadal steroids on the glucocorticoid-mediated regulation of the gene transcription of corticotropin-releasing hormone $(\mathrm{CRH})$ and corticosteroid receptors in brain areas of relevance for the control of pituitary-adrenal secretion. The efficacy of adrenalectomy (ADX) and chronic treatment with high doses of corticosterone (B) to regulate the gene transcription of $\mathrm{CRH}$ and corticosteroid receptors in the hypothalamic paraventricular nucleus (PVN) and hippocampus was studied in male and female rats under the conditions of deprivation of gonadectomy (GDX) and replacement with different gonadal steroids, such as estradiol $\left(E_{2}\right)$, progesterone $(P)$, and dihydrotestosterone (DHT). In both sexes, ADX alone or in combination with GDX increased, and B treatment suppressed, the steady-state levels of $\mathrm{CRH}$ and corticosteroid receptor mRNAs, whereas GDX alone failed to affect any of the parameters studied. Administration of gonadal hormones to steroid- deprived (ADX/GDX) animals partially attenuated the upregulation of mRNAs encoding corticosteroid receptors in the hippocampus. Supplementation with gonadal steroids modified the effects of $\mathrm{B}$ on the gene transcription of $\mathrm{CRH}$ and corticosteroid receptors. Whereas $\mathrm{P}$ alone or in combination with $\mathrm{E}_{2}$ counteracted the $\mathrm{B}$-induced downregulation of $\mathrm{GR}$ and $\mathrm{CRH}$ gene transcription in females, DHT and $\mathrm{E}_{2}$ administration further potentiated the effects of $B$ on these parameters in a sex-specific manner. Taken together, the results indicate that gonadal steroids have minor influence on MR, $\mathrm{GR}$, and $\mathrm{CRH}$ gene transcription under basal conditions, exert "glucocorticoid-like" effects on the transcription of corticosteroid receptors in the hippocampus of steroiddeprived animals, and interact with glucocorticoid-mediated mechanisms of regulation in the HPA axis through genderspecific "buffering" and "potentiating" effects.

Key words: sex steroids; corticotropin-releasing hormone $(\mathrm{CRH})$; corticosteroid receptors; gene expression; hypothalamus; hippocampus
Gonadal steroids are critically involved in several aspects of brain development and function, with considerable interest recently being generated in their role in the control of the hypothalamicpituitary-adrenal (HPA) system. Evidence accumulated over the last 30 years demonstrates that the neuroendocrine response to stress displays profound gender-specific differences, the manifestation of which largely depends on the presence of gonadal steroids (Kitay, 1961; Critchlow et al., 1963; Viau and Meaney, 1991; Burgess and Handa, 1992). Recent studies in our laboratory provided the first evidence that sex hormone-dependent organization of the brain during early postnatal development in the rat also results in the establishment of gender-specific patterns in the neural mechanisms controlling HPA activity, as reflected by distinct sex differences in the expression of genes encoding corticotropin-releasing hormone $(\mathrm{CRH})$ in the hypothalamus and corticosteroid receptors in the hippocampus (Patchev et al., 1995). In addition, we found that gender-specific differences in pituitary-

Received June 17, 1996; revised Aug. 8, 1996; accepted Aug. 14, 1996.

This work was supported by the Deutsche Forschungsgemeinschaft (SFB 220/TP 8). V.P. is the recipient of a research award of the Theodore and Vada Stanley Foundation. The expert assistance of Daniela Rouskova is gratefully acknowledged.

Correspondence should be addressed to Dr. Vladimir K. Patchev, Department of Neuroendocrinology, Max Planck Institute of Psychiatry, Clinical Institute, Kraepelinstrasse 2, 80804 Munich, Germany.

Copyright (C) 1996 Society for Neuroscience $0270-6474 / 96 / 167077-08 \$ 05.00 / 0$ adrenal hormone secretions and their sensitivity to glucocorticoid negative feedback are influenced by alterations in the gonadal steroid milieu in adulthood (O. Almeida, V. Canoine, S. Ali, F. Holsboer, and V. Patchev, unpublished observations). Taken together, these findings indicate that gonadal hormones apparently exert "organizing" and "activating" effects on several neural mechanisms that control HPA activity under basal and stressrelated conditions.

$\mathrm{CRH}$, produced in parvocellular neurons of the hypothalamic paraventricular nucleus $(\mathrm{PVN})$, is the major activator of the pituitary-adrenal secretory cascade, at least under physiological conditions. Its gene expression and release are tightly controlled by circulating glucocorticoids (Sawchenko, 1987; Swanson and Simmons, 1989). Type I (MR) and type II (GR) corticosteroid receptors (mineralocorticoid and glucocorticoid receptors, respectively) in the hippocampus, and GR in the PVN, are the principal mediators of corticosteroid negative feedback on the central components of the HPA axis (McEwen et al., 1986; Dallman et al., 1992; de Kloet et al., 1993); the gene expression and binding properties of these receptors are themselves subject to regulation by adrenocortical steroids (Spencer et al., 1991; Herman, 1993). Several previous studies have suggested an influence of the gonadal steroid milieu on CRH (Haas and George, 1988; Bohler et al., 1990; Almeida et al., 1992; Bingaman et al., 1994) 
and corticosteroid receptors (Turner and Weaver, 1985; Peiffer et al., 1991; Ahima et al., 1992; Carey et al., 1995; Castrén et al., 1995), although the contribution of the individual gonadal hormones to the regulation of HPA function remains obscure. The complexity of the problem emerges from two principal facts: (1) the activating effects of gonadal steroids occur secondarily to, and are dependent on, sex-specific organization of the brain; and (2) gonadal steroid secretions in males and females differ qualitatively, quantitatively, and temporally.

The present study was designed to investigate systematically the activating effects of individual gonadal steroids on the major central components of the HPA axis. Specifically, male and female rats were steroid-deprived by adrenalectomy (ADX) and gonadectomy (GDX) and then chronically exposed to fixed amounts of estradiol $\left(\mathrm{E}_{2}\right)$, progesterone $(\mathrm{P})$, and dihydrotestosterone (DHT); in one experiment, these gonadal steroid treatments were superimposed on chronic treatment with supraphysiological doses of corticosterone (B). The effects of these treatments on the transcription of genes encoding $\mathrm{CRH}, \mathrm{MR}$, and GR in selected brain regions were monitored by in situ hybridization histochemistry so as to shed light on (1) how GDX and the individual sex steroids influence the expression of CRH, MR, and GR genes, and (2) the ability of individual gonadal hormones to alter corticosteroidmediated effects on $\mathrm{CRH}, \mathrm{MR}$, and GR gene expression.

\section{MATERIALS AND METHODS}

General procedures. Sexually mature (3 month old) Wistar rats (Max Planck Institute of Biochemistry, Martinsried, Germany) were housed in groups of five under controlled illumination (12 hr light/dark cycle; lights on at 6:00 A.M.) and had free access to food and water throughout the experiment. All surgical and treatment procedures were conducted in compliance with national regulations on animal welfare. The stage of ovarian cycle was monitored daily for $10 \mathrm{~d}$ before experimentation in females that were to serve as intact controls. ADX and/or GDX were performed under barbiturate anesthesia $(30 \mathrm{mg} / \mathrm{kg}$ Brevimytal, i.p.; Lilly, Bad Homburg, Germany); sham-operated controls received skin incisions under barbiturate anesthesia. ADX rats were given physiological saline as drinking solution. In all experiments, rats were killed by decapitation between 9:00 A.M. and 12:00 P.M.; sham-operated female controls were killed on the day of diestrus. A specific RIA (ICN Biomedicals, Costa Mesa, CA) was used to assay B in plasma obtained from trunk blood at the time of killing. After killing, brains were rapidly removed, snap-frozen in prechilled isopentane, and stored at $-70^{\circ} \mathrm{C}$ before being processed for semiquantitative detection of $\mathrm{CRH}, \mathrm{MR}$, and GR mRNAs, as described below. In all experiments, treatment groups consisted of five animals each. All reagents, including steroids, were supplied by Sigma (Deisenhofen, Germany) unless stated otherwise.

Experiment 1: effects of adrenal and/or gonadal steroid deprivation. Intact (sham-operated), ADX, GDX, and ADX+GDX male and female rats were killed $6 \mathrm{~d}$ after surgical intervention, and their blood plasma and brains were retained and processed as described above.

In the next two experiments, we examined the effects of different steroid hormones; to eliminate the interference of endogenous steroids, the adrenals and gonads were removed in all subjects before starting hormone treatment.

Experiment 2: effects of sex hormone administration in steroid-deprived rats. Subgroups of ADX+GDX male and female rats were given subcutaneous injections of estradiol benzoate $\left(\mathrm{E}_{2} ; 50 \mu \mathrm{g}\right)$, progesterone $(\mathrm{P} ; 1$ $\mathrm{mg}$ ), and dihydrotestosterone (DHT; $100 \mu \mathrm{g}$ ) on the days 1, 3, and 5 after surgery. In addition, a group of female rats received $\mathrm{E}_{2}$ and $\mathrm{P}$ at the above-mentioned doses, but according to a sequential regimen: an injection of $E_{2}$ on the day 1 after surgery, followed by injections of $P$ on days 3 and 5 after surgery. The controls in this experiment consisted of $\mathrm{ADX}+\mathrm{GDX}$ male and female rats that received equivalent amounts $(0.5$ $\mathrm{ml})$ of vehicle (corn oil). Animals were killed $1 \mathrm{~d}$ after the last of the injections ( $6 \mathrm{~d}$ after surgery), their brains being collected for the measurement of mRNAs encoding CRH, MR, and GR (see above).

Experiment 3: effects of gonadal steroids in rats exposed to supraphysiological levels of $B$. Subgroups of male and female ADX + GDX rats were subcutaneously implanted with pellets containing $100 \mathrm{mg}$ of B (Innovative
Research of America, Sarasota, FL) immediately after surgery. Pellets were left in place for $6 \mathrm{~d}$. These animals were subject further to treatments consisting of gonadal steroids $\left(E_{2}, P, D H T\right.$, and $\left.E_{2}+P\right)$ or vehicle (corn oil); the latter were administered according to the dose- and time-schedules described for experiment 2. Rats were killed on day 6 after surgery, and their blood and brains were collected for determinations of B levels and quantification of mRNAs, respectively.

In situ hybridization histochemistry. Coronal cryosections $(14 \mu \mathrm{m})$, containing the rostral third of the hypothalamic PVN (rostro-caudal coordinates between bregma -1.4 and -1.6) and the dorsal hippocampus (between bregma -2.80 and -3.60 ), were thaw-mounted on gelatincoated slides; fixation, permeabilization, hybridization, and washing at high stringency were performed according to previously described protocols (Brady et al., 1990; Whitfield et al., 1990). An oligonucleotide 48-mer antisense probe, complementary to bases $496-543$ of the rat CRH gene (Jingami et al., 1985), was commercially synthesized (MWG-Biotech, Ebersberg, Germany) and labeled with $\left.{ }^{35} \mathrm{~S}\right] \mathrm{dATP}$ (DuPont NEN, Boston, MA) by terminal deoxynucleotidyl transferase. The plasmids containing the probes for the rat type I (MR) and type II (GR) corticosteroid receptors (Miesfeld et al., 1986; Arriza et al., 1988) were donated by Dr. L. Brady [National Institute of Mental Health (NIMH), Bethesda, $\mathrm{MD}]$. After linearization, $\left[{ }^{35} \mathrm{~S}\right] \mathrm{dUTP}$-labeled cRNA probes were generated by transcription from the SP6 (antisense) and T7 (sense) promoter, respectively. Autoradiographs from hybridized sections were generated by exposure to Hyperfilm $\beta$ max (Amersham, Little Chalfont, UK) for standardized periods. Specificity of the hybridization signals was monitored using adjacent sections that were hybridized with the corresponding sense probes. Autoradiographic signals in brain regions of interest (PVN and hippocampal subfield CA1/CA2) were quantified by computerassisted densitometry (National Institutes of Health Image 1.52; NIMH, Bethesda, MD).

Statistics. Four measurements of the optical density of hybridization signals for CRH, MR, and GR mRNAs in the areas of interest (PVN and hippocampus) were made on two consecutive sections from each animal and converted into $\mu \mathrm{Ci} / \mathrm{gm}$ tissue using a third-order polynomial equation generated from measurements in coexposed radioactive standards (ARC Inc., St. Louis, MO). These measurements were used to calculate individual means and, subsequently, group means. The latter, as well as group means of plasma B levels, were subjected to one-way ANOVA, followed by Dunnett's $t$ test, as appropriate, so as to examine differences between control and hormone-treated groups. The level of significance was preset at $p \leq 0.05$.

Comparisons between the magnitudes of response (CRH, MR, and GR mRNAs) to ADX and/or GDX, and supplementation with high doses of $\mathrm{B}$, were made on the basis of computations of percentage ratios between treatment effects in individual animals and the average intensity of hybridization signals in sham-operated controls; these ratios may be considered to reflect "relative steroid sensitivity" of the parameters studied. The existence of treatment-related statistical differences in the latter was examined using the nonparametric one-way ANOVA (KruskallWallis), followed by the Wilcoxon rank-sum test. Differences between means were considered significant when $p \leq 0.05$.

Because experiments with male and female subjects were conducted at different times, albeit under identical conditions, the numerical data were not used for direct comparisons of gender-specific differences.

\section{RESULTS}

Basal plasma levels of B in adrenal-intact rats ranged between 50 and $70 \mathrm{ng} / \mathrm{ml}$, with no significant differences detectable between the genders; GDX did not exert a significant influence on plasma B levels in either sex (data not shown). Subcutaneous B implants significantly elevated circulating levels of B to $223 \pm 43 \mathrm{ng} / \mathrm{ml}$; neither gender nor superimposed gonadal steroid treatments were associated with significant effects on the latter values.

\section{Effects of adrenal and gonadal steroid deprivation}

Both males and females responded to procedures involving ADX (ADX and ADX+GDX) with significant increases in hippocampal MR and GR mRNA levels, as well as in the number of CRH mRNA transcripts in the hypothalamic PVN. Levels of mRNA encoding MR in the hippocampus (Fig. 1, top panels) and CRH in the PVN (Fig. 1, bottom panels) were not affected by GDX alone. 

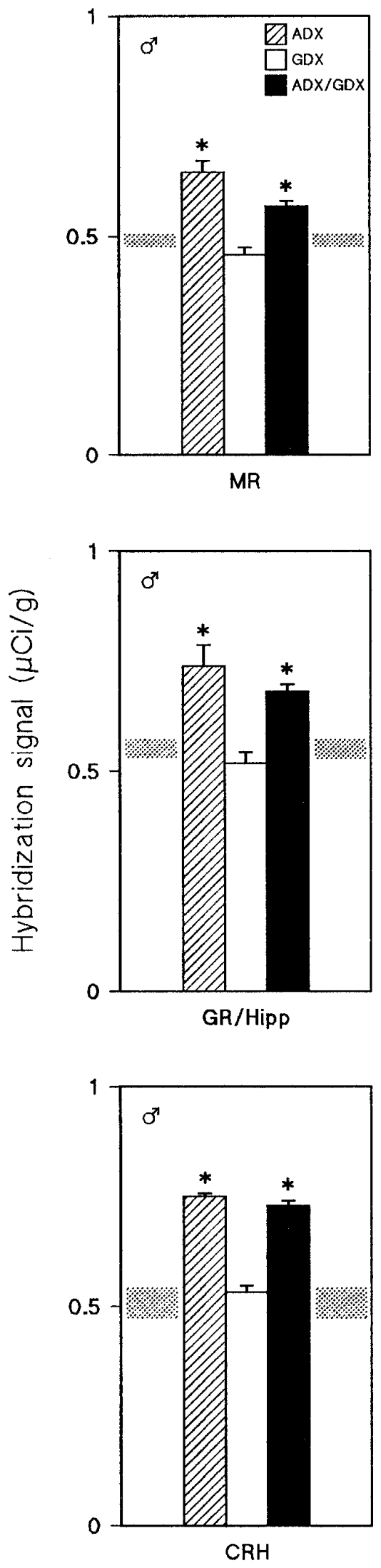
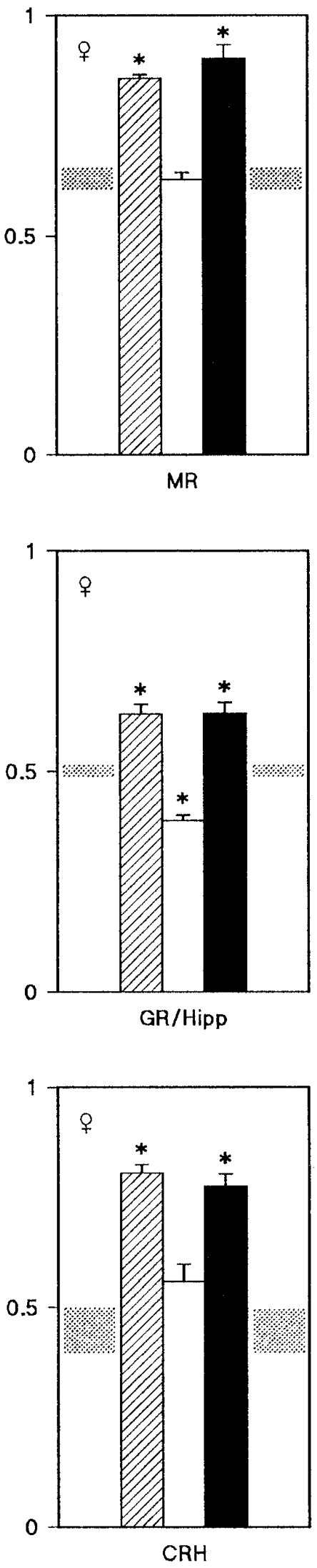

Figure 1. Effects of ADX (hatched bars), GDX (open bars), and $\mathrm{ADX}+\mathrm{GDX}$ (solid bars) on hybridization signals ( $\mu \mathrm{Ci} / \mathrm{gm}$ tissue) for mRNAs encoding MR and GR in the hippocampus and CRH in the PVN of male (left panels) and female (right panels $)$ rats. Shaded areas represent data $( \pm$ SEM range) obtained in sham-operated controls. All values shown represent mean $\pm \operatorname{SEM}(n=5$ per group). Asterisks denote significant differences from levels measured in sham-operated controls.
Whereas GDX did not significantly alter GR mRNA levels in the hippocampus of males, the manipulation induced a significant reduction in this parameter in females (compare open bars in Fig.
1, middle panels). Compared to males, females generally showed a greater relative responsiveness to ADX, GDX, and ADX+GDX (compare Table 1). Removal of the adrenals and/or gonads failed 
Table 1. Relative magnitude of ADX-, GDX-, and B-induced changes in mRNAs encoding hippocampal corticosteroid receptors and CRH in the PVN

\begin{tabular}{llccc} 
Treatment & Gender & MR mRNA & GR mRNA & CRH mRNA \\
\hline ADX & Males & $130.8 \pm 4.37$ & $126.4 \pm 6.31$ & $133.8 \pm 1.07$ \\
& Females & $126.5 \pm 0.64$ & $123.6 \pm 3.63$ & $156.8 \pm 4.07^{*}$ \\
GDX & Males & $95.8 \pm 3.47$ & $93.4 \pm 4.19$ & $101.4 \pm 1.83$ \\
& Females & $100.0 \pm 2.12$ & $78.0 \pm 2.42^{*}$ & $115.0 \pm 5.93$ \\
ADX+GDX & Males & $118.0 \pm 2.05$ & $119.6 \pm 2.20$ & $130.8 \pm 1.56$ \\
& Females & $130.8 \pm 2.52^{*}$ & $123.6 \pm 3.97$ & $151.0 \pm 5.03^{*}$ \\
ADX + GDX+B B & Males & $90.5 \pm 3.62$ & $68.8 \pm 2.44$ & $52.6 \pm 2.36$ \\
& Females & $94.2 \pm 2.42$ & $74.2 \pm 2.35$ & $81.2 \pm 4.41^{*}$
\end{tabular}

$\overline{\text { Data are given in percent (mean } \pm \text { SEM from } 5 \text { individuals) of the group average }}$ determined in sham-operated controls. Asterisks indicate significant gender differences $(p \leq 0.05)$.

to significantly alter GR mRNA levels in the PVN of either male or female animals (data not shown).

\section{Effects of sex hormone administration in ADX + GDX rats}

Selective steroid replacement in ADX + GDX male and female rats revealed gender-specific patterns of response in terms of hippocampal MR and GR gene expression (Fig. 2, top and middle panels), whereas hypothalamic CRH mRNA levels did not change in response to any of the gonadal steroid administration regimens (Fig. 2, bottom panels). Treatment with $\mathrm{E}_{2}$ resulted in a significant reduction in MR mRNA levels in females only (Fig. 2, top right panel); in contrast, $\mathrm{E}_{2}$-induced changes in GR mRNA levels were restricted to males that showed a significant reduction in this parameter (Fig. 2, middle left panel). The administration of $\mathrm{P}$ to $\mathrm{ADX}+\mathrm{GDX}$ male, but not female, rats resulted in a significant reduction in the gene expression of MR (Fig. 2, top left panel). Neither sex showed changes in GR mRNA levels in response to P treatment. Treatment of females with $\mathrm{P}$, subsequently to priming with $E_{2}$, resulted in an abolition of the suppressive effect of $E_{2}$ on MR gene expression (Fig. 2, top right panel). Although neither $\mathrm{E}_{2}$ nor $\mathrm{P}$ alone influenced GR gene expression in females, their sequential application resulted in a significant suppression of GR mRNA levels in the hippocampus (Fig. 2, middle right panel). Neither of the gonadal steroids used produced significant changes in GR gene transcription in the PVN of $\mathrm{ADX}+\mathrm{GDX}$ rats (data not shown).

\section{Effects of gonadal steroids in rats exposed to supraphysiological doses of corticosterone}

It should be noted that in the following descriptions, changes in any parameter refer to the sum effects of selective gonadal steroid treatments in $\mathrm{ADX}+\mathrm{GDX}$ rats supplemented with supraphysiological doses of $\mathrm{B}$. In each case, comparisons are made with values observed in vehicle (corn oil)-treated $\mathrm{ADX}+\mathrm{GDX}+\mathrm{B}$ implanted animals. In the latter groups, the hybridization signals for CRH, MR, and GR mRNAs were significantly lower than those seen in sham-operated controls (compare shaded areas in corresponding panels in Figs. 1 and 3), with males displaying a higher sensitivity to the action of B (compare Table 1).

Except for DHT, which caused a further decrease in males (Fig. 3, top left panel), gonadal steroid supplementation did not significantly influence MR gene expression in B-implanted rats. Whereas males were nonresponsive to gonadal steroid supplementation in terms of hippocampal GR gene expression, the latter parameter displayed a further significant reduction in females receiving $\mathrm{E}_{2}$ treatment (compare Fig. 3, middle right panel). $\mathrm{Fe}$ males treated with $\mathrm{P}$ alone, or $\mathrm{P}$ after priming with $\mathrm{E}_{2}$, had significantly higher GR mRNA levels than those measured in the reference group (Fig. 3, middle right panel). Administration of $\mathrm{E}_{2}$ to $\mathrm{ADX}+\mathrm{GDX}+\mathrm{B}$-supplemented rats failed to influence hypothalamic CRH gene expression. Whereas $\mathrm{P}$ did not cause any notable changes in the levels of CRH mRNA in males, female rats treated with $\mathrm{P}$ alone or in combination with $\mathrm{E}_{2}$, showed significant increases in the latter parameter compared to vehicle-injected animals (Fig. 3, bottom right panel). The androgen DHT proved to be an accessory suppressor of CRH mRNA levels in males but not females (Fig. 3, bottom left panel).

\section{DISCUSSION}

We previously showed that several differences in the activity of the HPA axis in male and female rats may be a consequence of exposure of the developing brain to gonadal hormone-dependent organization (Patchev et al., 1995). However, because the brain experiences its greatest exposure to gonadal steroids during a protracted period, spanning puberty and much of adulthood, the present study was undertaken to address the question of how circulating sex steroids influence or activate sexually differentiated neural mechanisms involved in HPA regulation. The rationale behind this question may be better appreciated by recalling a well documented parallel in reproductive neuroendocrinology in which activational effects of gonadal steroids on hormonal secretion and behavior are superimposed on perinatally organized neuroendocrine circuits (Goy and McEwen, 1980). In this work, carried out on postorganized adult male and female rats, we demonstrate that the major sex steroids $E_{2}, P$, a combination of $E_{2}$ and $P$ (in females only, to mimic the estrous cycle), and DHT exert activational effects on the transcription of genes encoding corticosteroid receptors (MR and GR) in the hippocampus and $\mathrm{CRH}$ in the paraventricular nucleus of the hypothalamus; these actions varied depending on the particular parameter investigated and also between the sexes. Because these studies concentrated on assaying steady-state levels of CRH-, MR-, and GR-encoding mRNAs, it is appropriate to mention at the outset of the discussion that several studies have shown a good correlation between these parameters and the amounts of their respective translational products (Swanson and Simmons, 1989; Herman, 1993).

In agreement with previous reports (Swanson and Simmons, 1989; Herman, 1993), ADX in both sexes was associated with significantly increased levels of mRNAs encoding CRH and corticosteroid receptors in the brain structures of interest. However, GDX affected only one of these latter parameters: in females, it caused a decrease in hippocampal GR mRNA levels. Although corticosteroids may therefore be considered to be the prime transcriptional regulators of $\mathrm{CRH}, \mathrm{MR}$, and GR genes, the last result, together with the observation that females display higher GR mRNA levels under basal conditions (Patchev et al., 1995), strongly indicates that ovarian steroids exert an important influence on the central mechanisms controlling HPA activity. Furthermore, the present observation that females show stronger responses than males to steroid deprivation (see Table 1) suggests that females are more sensitive to the tonic regulatory influences of physiological levels of glucocorticoids; the latter view is supported by the recent demonstration that female rats are more sensitive to the acute inhibitory actions of glucocorticoids (O. Almeida, V. Canoine, S. Ali, F. Holsboer, and V. Patchev, unpublished observations). Although these differences may result primarily from sexually differentiated brain mechanisms (Patchev 

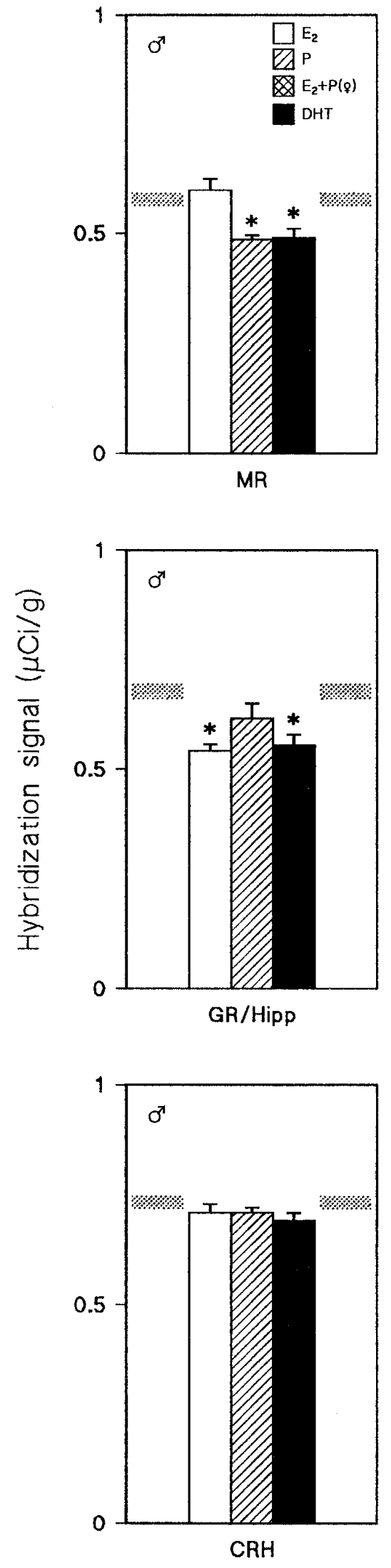
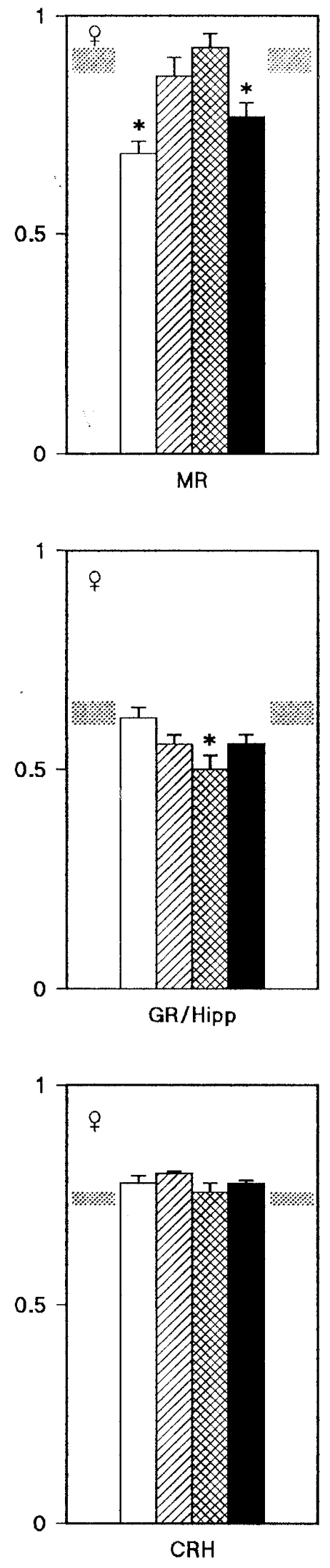

Figure 2. Changes in hybridization signals for $\mathrm{MR}, \mathrm{GR}$, and CRH mRNAs in ADX+GDX male (left panels) and female (right panels) rats, as induced by administration of $\mathrm{E}_{2}$ (open bars), $\mathrm{P}$ (hatched bars), $\mathrm{E}_{2}+\mathrm{P}$ (cross-hatched bars), and DHT (solid bars). Hybridization signals $(\mu \mathrm{Ci} / \mathrm{gm}$ tissue) measured in vehicle-treated $\mathrm{ADX}+\mathrm{GDX}$ rats are indicated by shaded areas. Asterisks denote significant effects as compared to vehicle-treated $\mathrm{ADX}+\mathrm{GDX}$ animals. Data represent mean \pm SEM of determinations in five individuals. et al., 1995), the notion that they are reinforced, or at least modulated, by exposure to activating gonadal steroids cannot be dismissed.
Examination of the effects of sex steroids on the transcription of MR and GR in the hippocampus of steroid-deprived animals (Fig. 2) revealed gender-specific profiles of the response to the individ- 

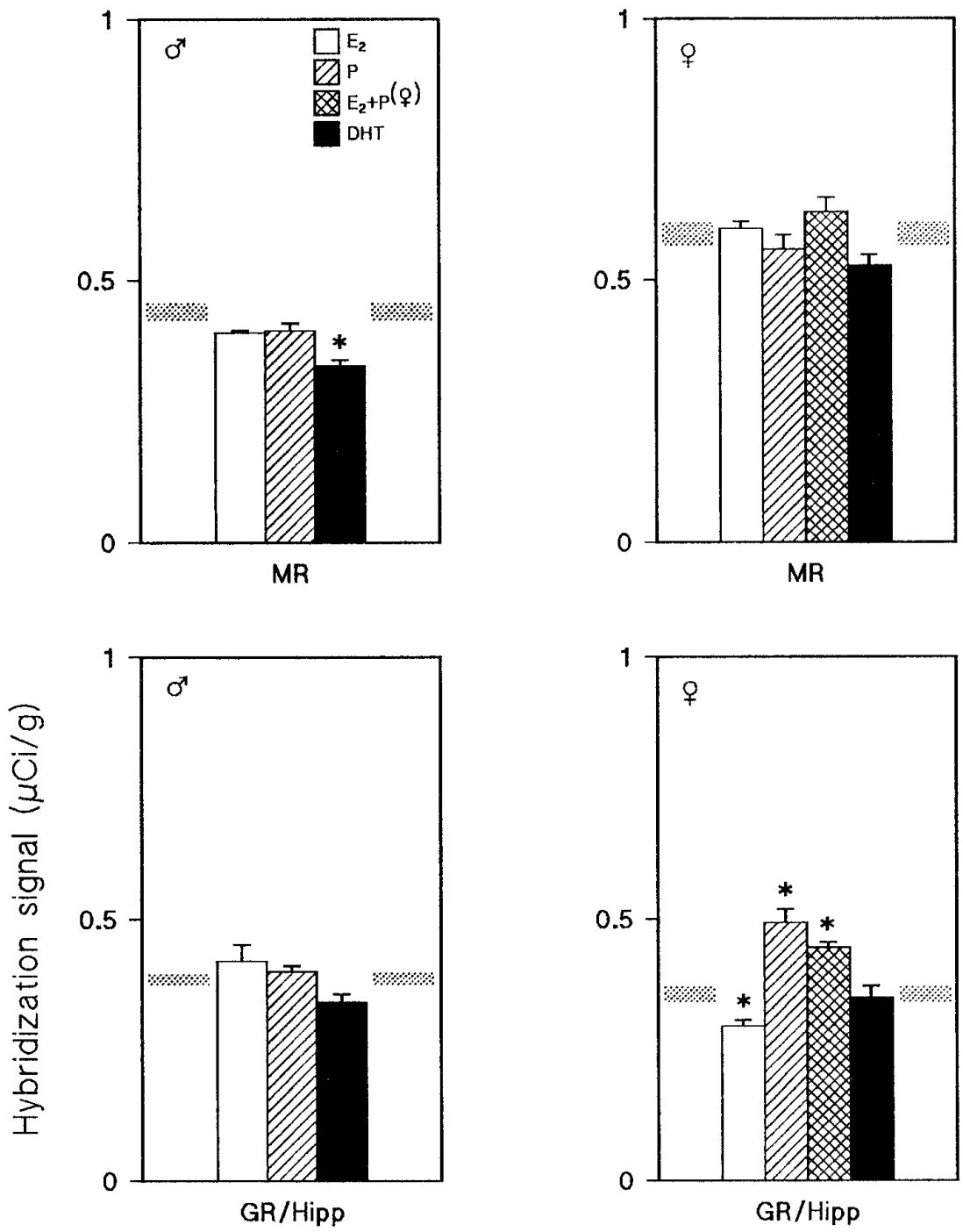

Figure 3. Effects of $\mathrm{E}_{2}$ (open bars), $\mathrm{P}$ (hatched bars), $\mathrm{E}_{2}+\mathrm{P}$ (cross-hatched bars), and DHT (solid bars) on MR, GR, and CRH mRNA levels in ADX+GDX male (left panels) and female (right panels) rats that were simultaneously exposed to supraphysiological doses of B. Shaded areas depict hybridization signals ( \pm SEM range) measured in B-implanted ADX + GDX animals receiving oil injections instead of gonadal steroids. Asterisks indicate significant differences between vehicle- and sex steroid-treated rats; data represent mean \pm SEM of five individuals.
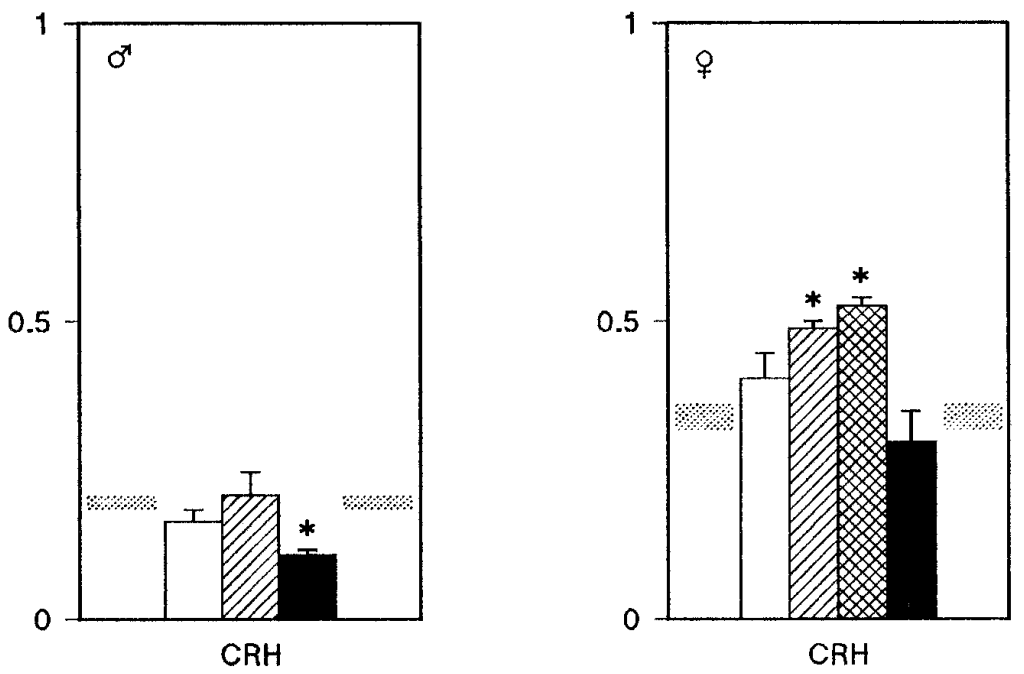

ual steroids tested. Overall, the gonadal steroids, irrespective of the class they belong to, attenuated the increases in MR and GR mRNAs resulting from the removal of the endogenous adrenocortical feedback. Interestingly, with the reservation that the ste- roids tested were applied at pharmacological doses, "typical" male (DHT) and female $\left(E_{2}, P\right)$ hormones exerted such effects even in the opposite sex; this is exemplified by the findings that $\mathrm{P}$ decreased MR gene expression in males (but not in females), 
whereas DHT reduced MR mRNA levels in females (as well as males). The glucocorticoid-like properties of these sex hormones point to the possibility that sex steroids might be able to serve as transcriptional regulators of genes normally considered to be (strictly) glucocorticoid-responsive. This view is consistent with earlier demonstrations that $\mathrm{P}$ interacts with MR gene transcription in the hippocampus (Castrén et al., 1995); some of the molecular mechanisms that might underlie such interactions are considered later in this discussion.

None of the sex steroid treatment regimens induced any changes in $\mathrm{CRH}$ gene expression in ADX + GDX male and female rats. Although an obvious interpretation of this observation is that gonadal steroids do not serve an activational role in the regulation of CRH synthesis, we consider this point worthy of further experimental investigation. For example, it could be that sex steroid effects were masked in the particular paradigm used in this work, i.e., that the ADX-induced increases in CRH mRNA levels had either already reached a "ceiling" or that any effects in the reverse direction could not be manifest at the steroid doses and/or duration of treatment used. Indeed, studies using other models have reported that estrogens and androgens influence CRH biosynthesis (Vamvakopoulos and Chrousos, 1993; Bingaman et al., 1994; Handa et al., 1994).

The third experiment in this study was designed to investigate whether sex steroids interfere, in an activational sense, with glucocorticoid feedback mechanisms: ADX +GDX animals received implants of corticosterone (resulting in constantly elevated plasma levels of B), and treatments with $\mathrm{E}_{2}, \mathrm{P}$, or DHT were then administered. As expected (Swanson and Simmons, 1989; Herman, 1993; Patchev et al., 1994), animals that received treatment with vehicle instead of the sex steroid treatment displayed reductions in their steady-state CRH, MR, and GR mRNA levels compared to sham-operated controls. Superimposed treatment with sex steroids resulted in changes that indicated an activating influence of gonadal hormones. For example, DHT treatment caused a further decline in the B-induced suppression of $\mathrm{CRH}$ and MR mRNA levels in males; a similar pattern was found in the case of GR gene expression in $\mathrm{E}_{2}$-supplemented females. In contrast, treatment of females either with $\mathrm{P}$ alone or with the combination of $\mathrm{E}_{2}+\mathrm{P}$ attenuated the $\mathrm{B}$-induced decreases in $\mathrm{CRH}$ and GR mRNA levels. Interestingly, in this paradigm, the typical male hormone (DHT) was only active in males, whereas the typical female steroids $\mathrm{P}$ and $\mathrm{E}_{2}$ elicited responses only in females. It is also worth emphasizing that, depending on the parameter measured, the sex steroids either potentiated (DHT, $E_{2}$ ) or allowed an "escape" from the suppressive effects of $B$. The latter, seen when $\mathrm{P}$ was administered to females, might also be viewed as buffering effects and raises the possibility that physiological rises in the secretion of $\mathrm{P}$ in females may represent endogenous "protectants" against the biological consequences of chronically elevated glucocorticoids. Support for this view is gained from previous reports suggesting that, if provided in sufficient concentrations, $\mathrm{P}$ may interfere with glucocorticoid receptormediated signals (Keller-Wood et al., 1988; Svec, 1988; Ahima et al., 1992; Young, 1995).

The mechanisms by which gonadal steroids exert their potentiating and buffering effects on glucocorticoid-mediated regulation of CRH, MR, and GR gene expression remain to be defined. However, the facts that (1) the various steroid receptors display extensive homology in their DNA-binding domains (CarsonJurica et al., 1991; Wahli and Martinez, 1991), and (2) at least some steroid receptors may form heterodimers (Trapp et al.,
1994) offer speculative avenues that deserve exploration in the future. In the context of the above remarks regarding mechanisms, it is pertinent to point out that gonadal steroid receptors have been described in the hippocampus (Loy et al., 1988; Simerly et al., 1990; Hagihara et al., 1992) and anatomical structures that innervate the PVN (for review, see Madeira and Lieberman, 1995), whereas sex hormone receptor expression in the PVN per se is rather modest (Pelletier et al., 1988; Simerly et al., 1990). These observations imply that whereas gonadal steroids may directly modulate corticosteroid receptor synthesis in the hippocampus (in concert with endogenous glucocorticoids), sex steroid effects on $\mathrm{CRH}$ gene transcription may involve trans-synaptic pathways.

In summary, the data presented here demonstrate the following: (1) in both sexes, adrenal corticosteroids act as major regulators of the transcription of genes encoding $\mathrm{CRH}, \mathrm{MR}$, and GR; (2) in the absence of adrenal secretions, gonadal steroids exert glucocorticoid-like effects on the gene expression of corticosteroid receptors in the hippocampus, while not affecting CRH mRNA levels in the PVN; and (3) sex steroids potentiate and buffer glucocorticoid feedback on the gene expression of $\mathrm{CRH}, \mathrm{MR}$, and GR in a gender-specific manner. The results may be implicated in the mechanisms underlying sex differences in the susceptibility to stress, as well as to dysregulation of HPA function after chronic exposure to excessive amounts of glucocorticoids. The latter has been the center of much recent psychiatric research because it may be causally linked to mood disorders such as major depression (for review, see Sapolsky and Plotsky, 1990; Young, 1995). The relevance of studies such as those initiated here can be better appreciated when one considers the statistically proven prevalence of depression in women (Kessler et al., 1993; Weissman et al., 1993). Experimental evidence demonstrating the neurotrophic properties of at least some gonadal steroids (Gould et al., 1991; Matsumoto, 1991; Miranda et al., 1993) might serve as a basis for examining whether gonadal steroids can be used therapeutically to modify the susceptibility of brain structures to the detrimental effects of chronically elevated glucocorticoids.

\section{REFERENCES}

Ahima RS, Lawson ANL, Osei SYS, Harlan RE (1992) Sexual dimorphism in regulation of type II corticosteroid receptor immunoreactivity in the rat hippocampus. Endocrinology 131:1409-1416.

Almeida OFX, Hassan AHS, Harbuz MS, Linton EA, Lightman SL (1992) Hypothalamic corticotropin-releasing hormone and opioid peptide neurons: functional changes after adrenalectomy and/or castration. Brain Res 571:189-198.

Arriza JL, Simerly WB, Swanson LW, Evans RM (1988) The neuronal mineralocorticoid receptor as a mediator of the glucocorticoid response. Neuron 1:887-900.

Bingaman EW, Magnuson DJ, Gray TS, Handa RJ (1994) Androgen inhibits the increases in hypothalamic corticotropin-releasing hormone $(\mathrm{CRH})$ and $\mathrm{CRH}$-immunoreactivity following gonadectomy. Neuroendocrinology 59:228-234.

Bohler Jr HCL, Zoeller RT, King JC, Rubin BS, Merriam GR (1990) Corticotropin-releasing hormone mRNA is elevated on the afternoon of proestrus in the parvocellular paraventricular nuclei of the female rat. Mol Brain Res 8:259-262.

Brady LS, Smith M, Gold PW, Herkenham M (1990) Altered expression of hypothalamic neuropeptide mRNA in food-restricted and fooddeprived rats. Neuroendocrinology 52:441-447.

Burgess LH, Handa RJ (1992) Chronic estrogen-induced alterations in adrenocorticotropin and corticosterone secretion, and glucocorticoid receptor-mediated functions in female rats. Endocrinology 131:1261-1269.

Carey MP, Deterd CH, de Koning J, Helmerhorst F, de Kloet ER (1995) The influence of ovarian steroids on hypothalamic-pituitary-adrenal regulation in the female rat. J Endocrinol 144:311-321. 
Carson-Jurica MA, Schrader WT, O’Malley BW (1991) Steroid receptor family: structure and functions. Endocr Rev 11:201-220.

Castrén M, Patchev VK, Almeida OFX, Holsboer F, Trapp T, Castrén E (1995) Regulation of rat mineralocorticoid receptor expression in neurons by progesterone. Endocrinology 136:3800-3806.

Critchlow V, Liebelt RA, Bar-Sela M, Mountcastle W, Lipscomb HS (1963) Sex difference in resting pituitary-adrenal function in the rat. Am J Physiol 205:807-815.

Dallman MF, Akana SF, Scribner KA, Bradbury MJ, Walker C-D, Strack AM, Cascio CS (1992) Stress, feedback and facilitation in the hypothalamo-pituitary-adrenal axis. J Neuroendocrinol 4:517-526.

de Kloet ER, Oitzl MS, Joëls M (1993) Functional implications of brain corticosteroid receptor diversity. Cell Mol Neurobiol 13:433-455.

Gould E, Wooley CS, McEwen BS (1991) The hippocampal formation: morphological changes induced by thyroid, gonadal and adrenal hormones. Psychoneuroendocrinology 16:67-84.

Goy RW, McEwen BS (1980) Sexual differentiation of the brain. Cambridge: MIT.

Haas DA, George SR (1988) Gonadal regulation of corticotropinreleasing factor immunoreactivity in hypothalamus. Brain Res Bull 20:361-367.

Hagihara K, Hirata S, Osada T, Hirai M, Kato J (1992) Distribution of cells containing progesterone receptor mRNA in the female rat di- and telencephalon: an in situ hybridization study. Mol Brain Res 14:239-249.

Handa RJ, Nunley KM, Lorens SA, Louie JP, McGivern RF, Bollnow MR (1994) Androgen regulation of adrenocorticotropin and corticosterone secretion in the male rat following novelty and footshock stressors. Physiol Behav 55:117-124.

Herman JP (1993) Regulation of adrenocorticosteroid receptor mRNA expression in the central nervous system. Cell Mol Neurobiol 13:349-371.

Jingami H, Mizuno N, Takahashi S, Shibahara S, Furutani Y, Imura H, Numa S (1985) Cloning and sequence analysis of cDNA for rat corticotropin-releasing factor precursor. FEBS Lett 191:63-66.

Keller-Wood M, Silbiger J, Wood CE (1988) Progesterone attenuates the inhibition of adrenocorticotropin responses by cortisol in nonpregnant ewes. Endocrinology 123:647-651.

Kessler RC, McGonagle KA, Swartz M, Blazer DG, Nelson CB (1993) Sex and depression in the National Comorbidity Survey. I. Lifetime prevalence, chronicity and recurrence. J Affect Disord 29:85-96.

Kitay JI (1961) Sex differences in adrenal cortical secretion in the rat. Endocrinology 68:818-824.

Loy R, Gerlach JL, McEwen BS (1988) Autoradiographic localization of estradiol-binding neurons in the rat hippocampal formation and entorhinal cortex. Dev Brain Res 39:245-251.

Madeira MD, Lieberman AR (1995) Sexual dimorphism in the mammalian limbic system. Prog Neurobiol 45:275-333.

Matsumoto A (1991) Synaptogenic action of sex steroids in developing and adult neuroendocrine brain. Psychoneuroendocrinology 16:25-40.

McEwen BS, de Kloet ER, Rostene W (1986) Adrenal steroid receptors and actions in the nervous system. Physiol Rev 66:1121-1188.

Miesfeld R, Rusconi S, Godowski PJ, Maler BA, Okret S, Wikström A-K, Gustafsson J-Å (1986) Genetic complementation of a glucocorticoid receptor deficiency by expression of cloned receptor cDNA. Cell 46:389-399.

Miranda RC, Sohrabji F, Toran-Allerand CD (1993) Presumptive estrogen target neurons express mRNAs for both neurotrophins and neuro- trophin receptors: a basis for potential developmental interactions of estrogen with the neurotrophins. Mol Cell Neurosci 4:510-525.

Patchev VK, Brady LS, Karl M, Chrousos GP (1994) Regulation of HSP90 and corticosteroid receptor mRNA by corticosterone levels in vivo. Mol Cell Endocrinol 103:57-64.

Patchev VK, Hayashi S, Orikasa C, Almeida OFX (1995) Implications of estrogen-dependent brain organization for gender differences in hypothalamo-pituitary-adrenal regulation. FASEB J 9:419-423.

Peiffer A, Lapointe B, Barden N (1991) Hormonal regulation of type II glucocorticoid receptor messenger ribonucleic acid in rat brain. Endocrinology 129:2166-2174.

Pelletier G, Liao N, Follea N, Govindan MV (1988) Mapping of estrogen receptor-producing cells in the rat brain by in situ hybridization. Neurosci Lett 94:23-28.

Sapolsky RM, Plotsky PM (1990) Hypercorticalism and its possible neural bases. Biol Psychiatry 27:937-952.

Sawchenko PE (1987) Adrenalectomy-induced enhancement of CRF and vasopressin immunoreactivity in parvocellular neurosecretory neurons: anatomic, peptide, and steroid specificity. J Neurosci 7:1093-1106.

Simerly RB, Chang C, Muramatsu M, Swanson LW (1990) Distribution of androgen and estrogen receptor mRNA-containing cells in the rat brain: an in situ hybridization study. J Comp Neurol 294:76-95.

Spencer RL, Miller AH, Stein M, McEwen BS (1991) Corticosterone regulation of type I and type II adrenal steroid receptors in brain, pituitary, and immune tissue. Brain Res 549:236-246.

Svec F (1988) Differences in the interaction of RU 486 and ketoconazole with the second binding site of the glucocorticoid receptor. Endocrinology 123:1902-1906.

Swanson LW, Simmons DM (1989) Differential steroid hormone and neural influences on peptide mRNA levels in CRH cells of the paraventricular nucleus: a hybridization histochemical study in the rat. J Comp Neurol 285:413-435.

Trapp T, Rupprecht R, Castrén M, Reul JMHM, Holsboer F (1994) Heterodimerization between mineralocorticoid and glucocorticoid receptor: a new principle of glucocorticoid action in the CNS. Neuron 13:1-20.

Turner BA, Weawer DA (1985) Sexual dimorphism of glucocorticoid binding in rat brain. Brain Res 343:16-23.

Vamvakopoulos NC, Chrousos GP (1993) Evidence of direct estrogenic regulation of human corticotropin-releasing hormone gene expression: potential implications for the sexual dimorphism of the stress response and immune/inflammatory reaction. J Clin Invest 92:1896-1902.

Viau V, Meaney MJ (1991) Variations in the hypothalamic-pituitaryadrenal response to stress during the estrous cycle in the rat. Endocrinology 129:2503-2511.

Wahli W, Martinez E (1991) Superfamily of steroid nuclear receptors: positive and negative regulators of gene expression. FASEB J 5:2243-2249.

Weissman MM, Bland R, Joyce PR, Newman S, Wells EJ, Wittchen H-U (1993) Sex differences in rates of depression: cross-national perspectives. J Affect Disord 29:77-84.

Whitfield Jr HJ, Brady LS, Smith MA, Mamalaki E, Fox R, Herkenham M (1990) Optimization of cRNA probe in situ hybridization methodology for localization of glucocorticoid receptor mRNA in rat brain: a detailed protocol. Cell Mol Neurobiol 10:145-157.

Young EA (1995) Glucocorticoid cascade hypothesis revisited: role of gonadal steroids. Depression 3:20-27. 